\title{
THE OUTBREAK OF NOVEL CORONAVIRUS DISEASE (COVID-19) PANDEMIC: CONSEQUENCES ON PUBLIC MENTAL HEALTH
}

\author{
S. M. Khaled \\ Hossain $^{1+}$ \\ Mahfuza Akhter ${ }^{2}$
}

\author{
'Lecturer, Army Institute of Business Administration (Army IBA), Savar \\ Cantonment, Dhaka, Bangladesh. \\ Email:smkhossain19@gmail.com Tel:(+88)01920-382951 \\ ${ }^{2}$ Undergraduate Student, Department of Political Science, National \\ University, Gazipur, Bangladesh. \\ Email:mahfuza.smk@gmail.com Tel:(+88)o1729-788459
}

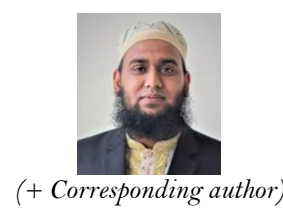

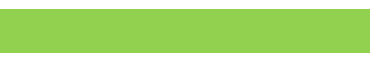

Article History

Received: 11 May 2020 Revised: 19 May 2020

Accepted: 27 May 2020

Published: 3 June 2020

\section{Keywords}

COVID-19

Pandemic

Epidemic

Depression

Anxiety

Stress.

\section{ABSTRACT}

The purpose of the current study is to investigate the impact of novel coronavirus disease (COVID-19) pandemic on the mental health of people living in Bangladesh. Data required for conducting the study were collected from 1000 respondents of Bangladesh especially in reference to Dhaka and Mymensingh districts through serving a structured questionnaire. The sample size was selected by using convenient sampling technique. DASS-21 was used to assess the mental health indicated by level of depression, anxiety and stress among the target respondents. The study found that level of depression; anxiety and stress differ in accordance with the gender, age, marital status, education, employment and professional status. The research result showed that, there is significant difference among gender, age, marital status, educational qualification and professional status in regard to depression, anxiety and stress level whereas there is no significant difference among employment status in regard to depression, anxiety and stress level of the respondents.

Contribution/Originality: The findings and output of the study will play a crucial role in measuring the level of depression, anxiety and stress created by COVID-19 pandemic among the community of Bangladeshi people. The study has value for future empirical and conceptual review to the researchers for conducting extensive study in this particular arena.

\section{INTRODUCTION}

At the time of any epidemic of an infectious disease, the mental reactions of inhabitants of that particular region keeps a very significant role in shaping both spread of the disease and the happening of emotional sufferings. The epidemic also leads to social disarray throughout the period and after the outbreak (Cullen, Gulati, \& Kelly, 2020). It is just four months back on 31 December, 2019 when the outbreak of a coronavirus infection (COVID-19) contaminated among the human community in Wuhan, the capital city of Hubei province in the People's Republic of China. After the outbreak of this global infectious disease from China an increasing number of information and concerns are influencing on global mental health (Torales, O’Higgins, Castaldelli-Maia, \& Ventriglio, 2020). This infectious disease which started as an epidemic in China during the infant stage was declared as a pandemic by World Health Organization (WHO) in 11 March, 2020. "Pandemic" is a word which is originated from Greek word "Pandemos". There are two parts of the word "Pandemos" wherein "pan" means "all" and "demos" stands for "people or population". So literally the word "pandemic" reflects an epidemic which not affects a particular community only 
rather than affects nearly all of the people and is not contaminated in any particular region rather than spreads all through the communities by crossing the international boundaries. The World Health Organization (WHO) defined the word "epidemic" as the regional outbreak of any disease which spreads unpredictably. It means to an increase, often sudden, in the number of cases of a disease beyond what is normally predictable among the population of an area.

There are total 2719897 confirmed cases globally till now (25 April, 2020) including -13,14,666 cases in Europe, 10,47,508 cases in Americas, 1,54,971 cases in Eastern Mediterranean, 1,41,470 cases in Western Pacific, 41,073 cases in South-East Asia and 19497 cases in Africa. Among the total confirmed cases approximately 1,87,705 deaths committed till now (25 April, 2020) by Coronavirus infection globally including -1,19,463 deaths in Europe, 53,103 deaths in Americas, 6,750 deaths in Eastern Mediterranean, 5,906 deaths in Western Pacific, 1,658 deaths in South-East Asia and 812 deaths in Africa (World Health Organization, April 2020). It was 8 March, 2020 when Bangladesh experienced Coronavirus active case for the first time. The number of active cases and deaths are increasing day by day. Still now there are 4998 positive cases and 140 deaths all over the country as on 25 April, 2020 (IEDCR, 2020).

The literature of earlier studies argued that COVID-19 pandemic not only affects physical health, but also psychological health (Brooks et al., 2020; Shigemura, Ursano, Morganstein, Kurosawa, \& Benedek, 2020). Fiorillo and Gorwood (2020) found in their research that, the psychosocial consequences of the COVID-19 pandemic may be particularly serious for those people who are into following four groups: (a) those who have been directly or indirectly in contact with the virus; (b) those who are already vulnerable to biological or psychosocial stressors (including people affected by mental health problems); (c) health professionals (because of higher level of exposure); and (d) even people who are following the news through numerous media channels.

The current study is designed to investigate the consequences of coronavirus disease on mental health of general people living in Bangladesh. The findings and output of the study will play a crucial role in measuring the level of depression, anxiety and stress created by COVID-19 among the community of Bangladeshi people. The study has value for future empirical and conceptual review to the researchers for conducting extensive study in this particular arena. In the first section of the study the statement of problems, purposes of the study are mentioned. In the next section the researchers pointed out all the related literatures in relation to the study. In the next section the methodological aspects of the study are described. The following section consists of data analysis and findings. Finally, at the last section of the study mentioned major findings and makes some recommendations in order to improve the current scenario.

\section{OBJECTIVES OF THE STUDY}

The study aims to attain the following particular objectives:

1. To draw an overview of present scenario of coronavirus disease in Bangladesh and around the globe.

2. To investigate the impact of COVID-19 pandemic on psychological health of people living in Bangladesh by measuring their depression, anxiety and stress level.

3. To make some recommendations for policy implications to improve the current situation.

\section{LITERATURE REVIEW}

\subsection{Outbreak of Novel Coronavirus (COVID-19)}

The 2019 novel coronavirus (2019-nCoV, COVID-19) has been detected as the pathogen following the pneumonia epidemic in Wuhan, Hubei Province, China, on December 8, 2019. It was January 20, 2020 just four months back from now when in South Korea, the country's first patient (who flew in from Wuhan) was detected (Ryu \& Chun, 2020). The number of confirmed cases was remained relatively stable till February 17, 2020 with only 30 diagnosed patients; however, the situation changed drastically and dramatically after the detection of the 31 st 
patient, and the number of confirmed cases jumped to 2,022 by February 28, 2020. The Wuhan City of China is in the spotlight since December 2019 as because of the outburst of a febrile respiratory syndrome owing to a pneumonia happened by a new unfamiliar coronavirus (Li, Song, Wong, \& Cui, 2020) perhaps associated to a wholesale seafood market in Huanan (Chen, Liu, \& Guo, 2020).

The new coronavirus (SARS-CoV-2, initially named 2019-nCoV) has been isolated from a patient in a short time on January 7, 2020, and the genome sequencing of this virus has been conducted (Lu, Stratton, \& Tang, 2020). The genetic sequence of SARS-CoV-2 has been formally documented by World Health Organization (WHO) on January 12, 2020. This process has led to the improvement of specific polymerase chain reaction PCR-based diagnostic tests to identify the new contamination in different countries (Corman et al., 2020). SARSCoV- 2, formerly denoted as an unfamiliar beta-coronavirus, is the seventh member of coronaviruses' family which infects humans, different from both MERS-CoV and SARSCoV, SARS-CoV-2 (Zhu et al., 2020). This outbreak is probably connected to the sale of bush meat of wild animal in the seafood market (Cui, Li, \& Shi, 2019). Apparently it seems that, the coronavirus disease originated from a sea food market of Wuhan, Hubei Province, China, where wild animals, rabbits, birds, marmots, bats, snakes etc are traded. It is a well-known fact that coronaviruses can jump from animals to humans. So it assumes that the first people who have infected with this disease are primarily from the sea food market from being in touch with animals (WHO, 2020). Still now the source of COVID-19 disease is unknown and scientists around the globe are working restlessly to find out the root cause of this disease. Zhou, Yang, Wang et al., 2020 from the Wuhan Institute for Virology released a detailed paper in which he shows that the new coronaviruses' genetic structure is 96 per cent identical to that of a coronavirus found in bats.

\subsection{Current Scenario of Novel Coronavirus (COVID-19) Infections around the World}

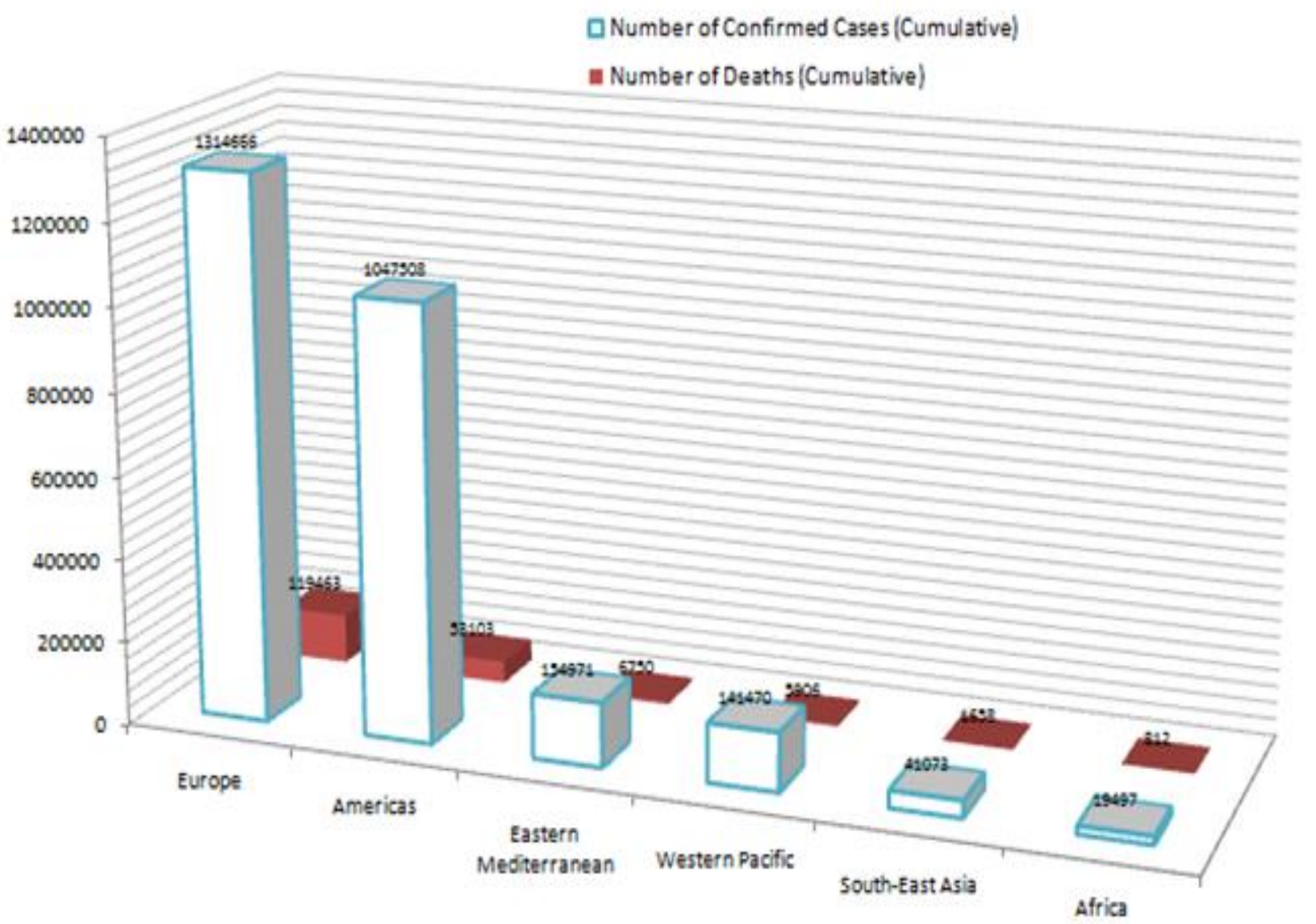

Figure-1. Number of cumulative confirmed cases and deaths according to WHO regions (Up to 25 April, 2020). Source: World Health Organization (April, 2020). 


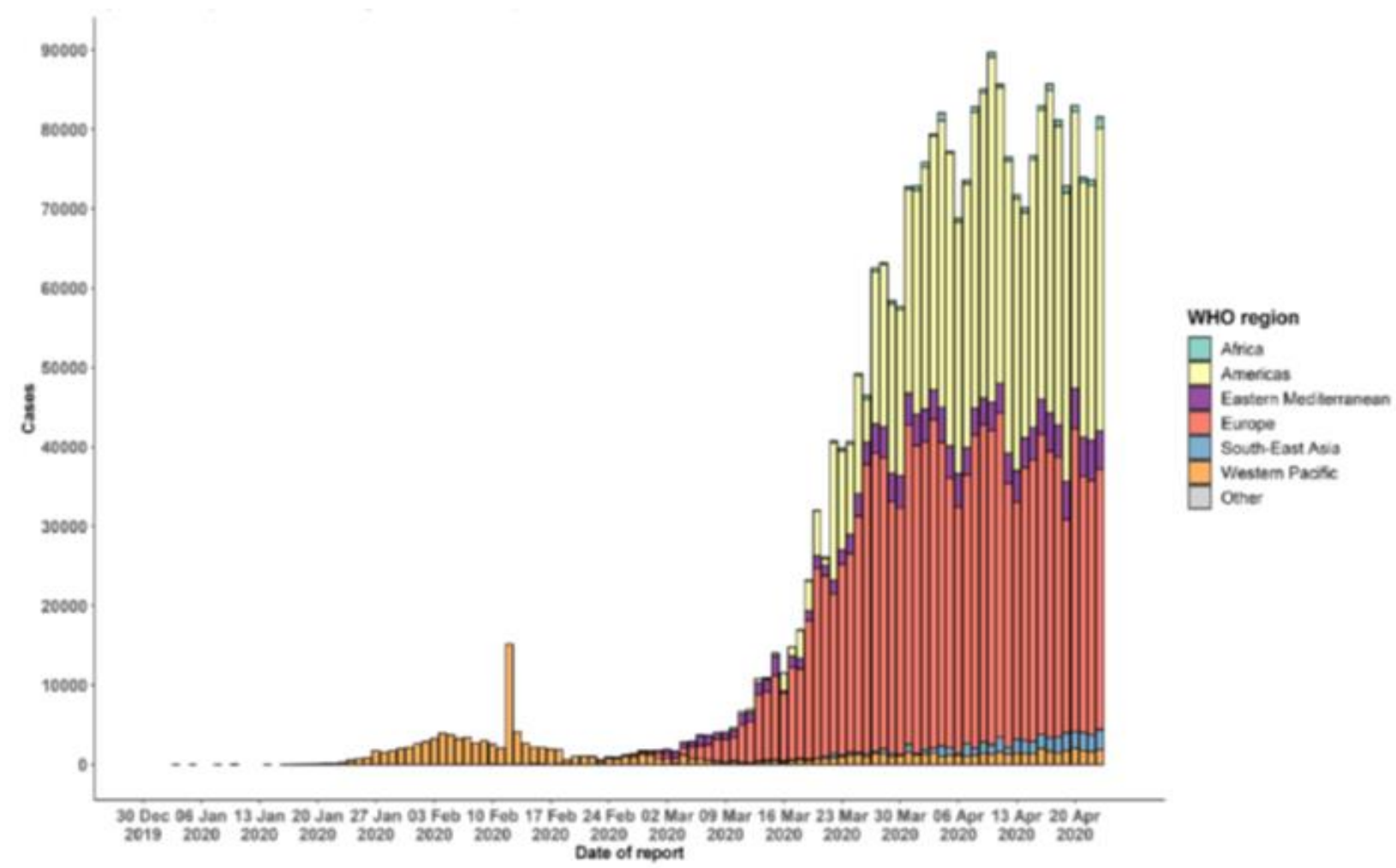

Figure-2. Number of cumulative confirmed cases according to WHO regions (Up to 25 April, 2020). Source: World Health Organization (April, 2020).

Figure 1 shows that, there are total 2719897 confirmed cases globally till now (25 April, 2020) including 13,14,666 cases in Europe, 10,47,508 cases in Americas, 1,54,971 cases in Eastern Mediterranean, 1,41,470 cases in Western Pacific, 41,073 cases in South-East Asia and 19,497 cases in Africa. Among the total confirmed cases approximately 1,87,705 deaths committed till now (25 April, 2020) by Coronavirus infection globally including 1,19,463 deaths in Europe, 53,103 deaths in Americas, 6,750 deaths in Eastern Mediterranean, 5,906 deaths in Western Pacific, 1,658 deaths in South-East Asia and 812 deaths in Africa (World Health Organization, April 2020). Figure 2 also describes a summary of total confirmed cases according to regions of World Health Organization which is a great concerning issue for today's world.

\subsection{Current Scenario of Novel Coronavirus (COVID-19) Infections in Bangladesh}

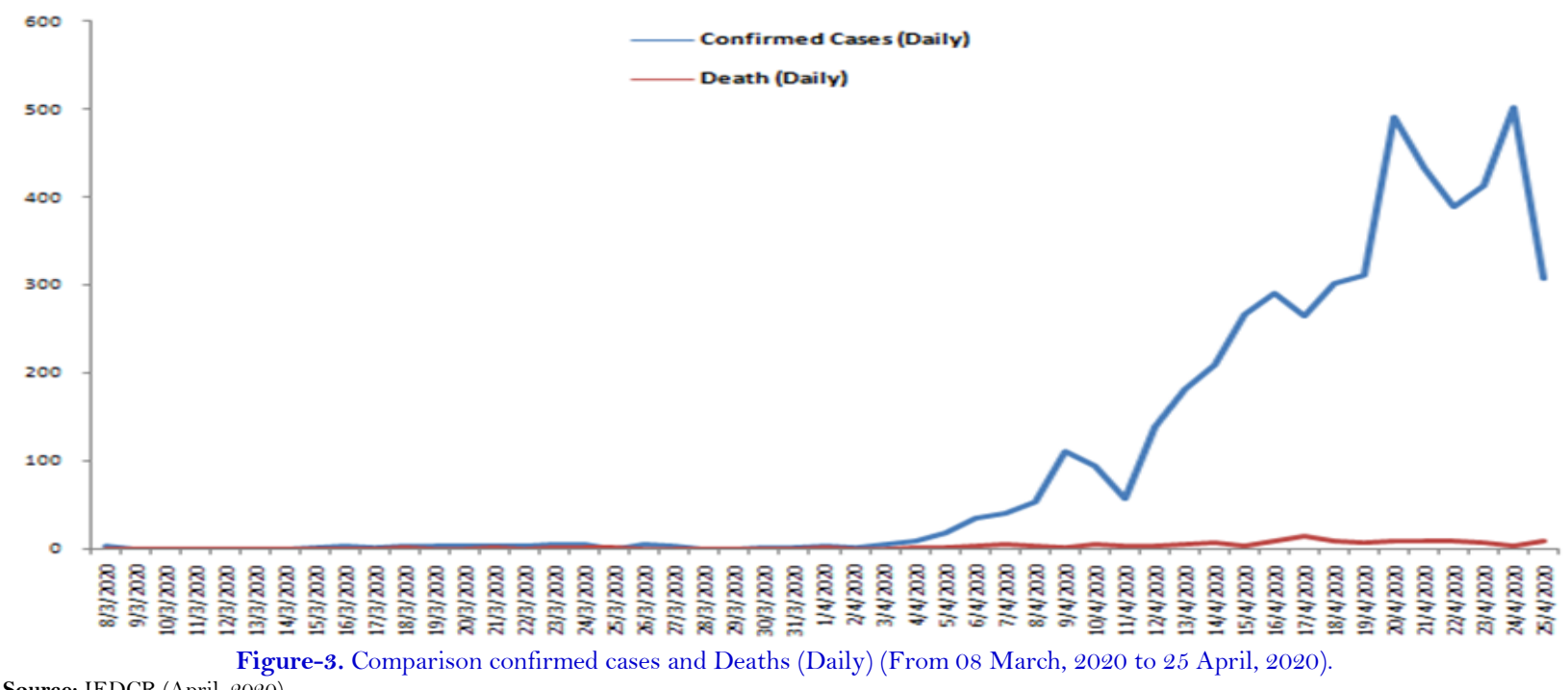

Source: IEDCR (April, 2020). 

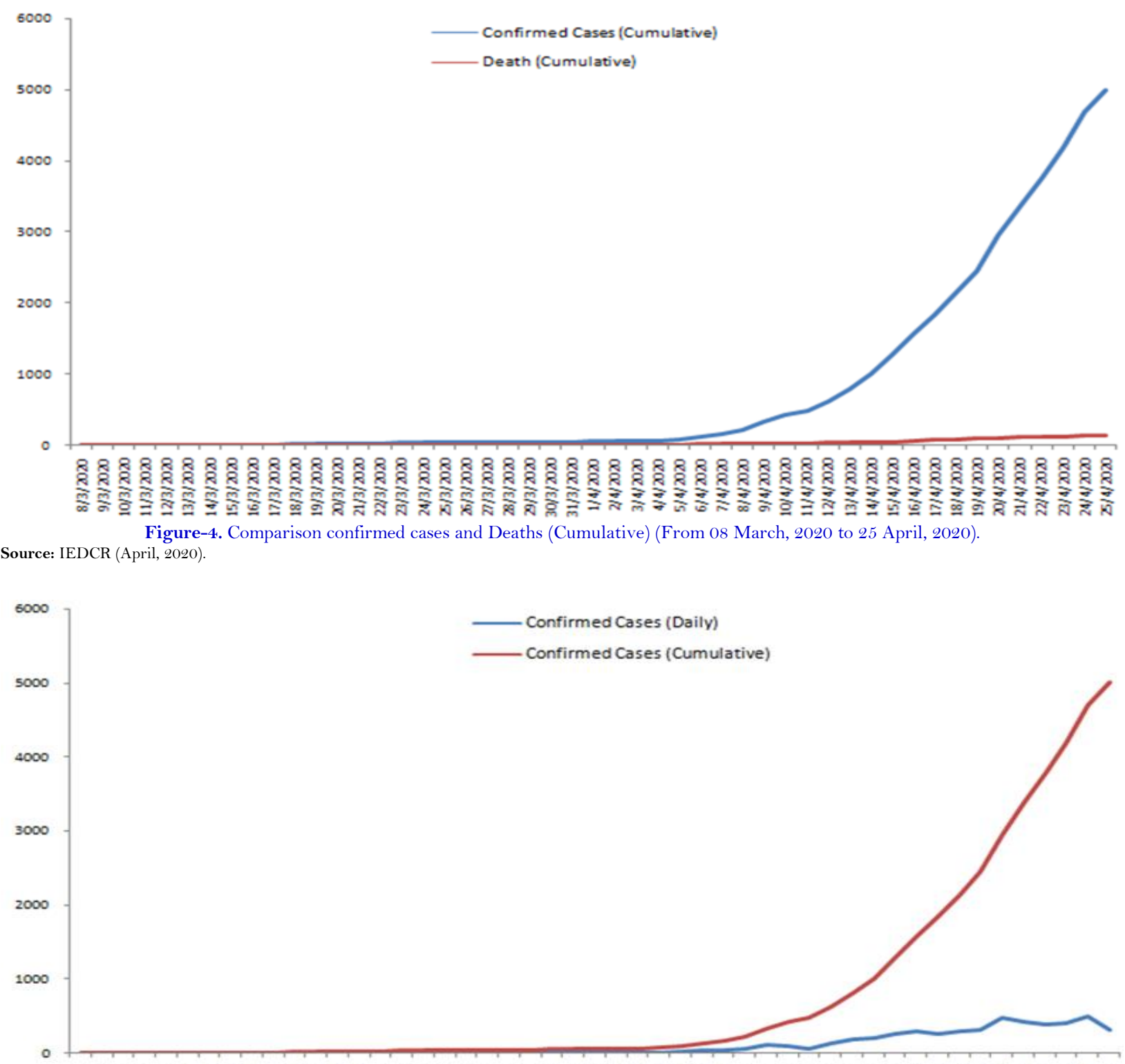

\& \&

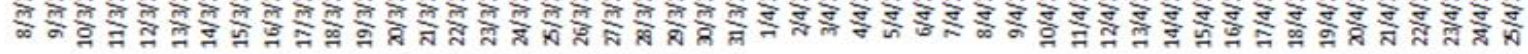

Figure-5. Comparison of daily confirmed cases and cumulative confirmed cases (From 08 March, 2020 to 25 April, 2020). Source: IEDCR (April, 2020).

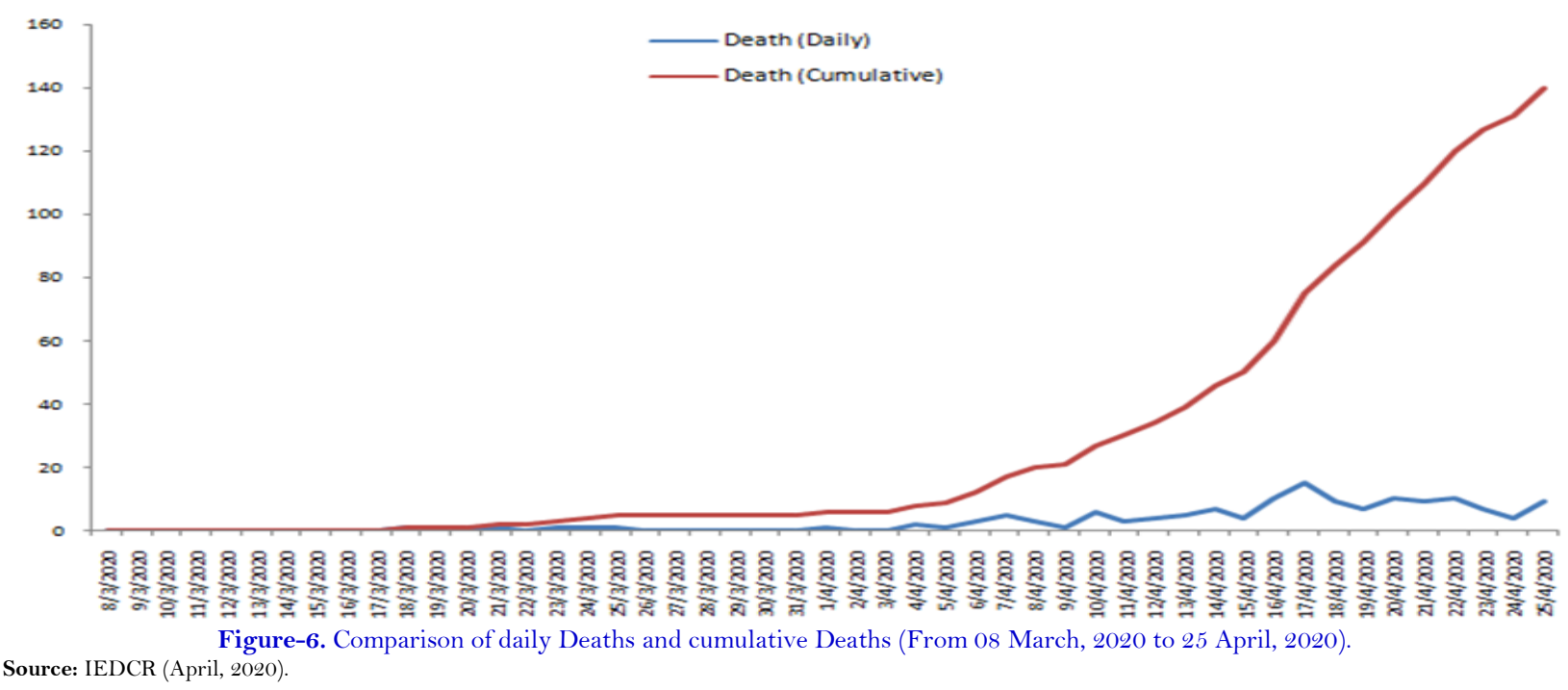




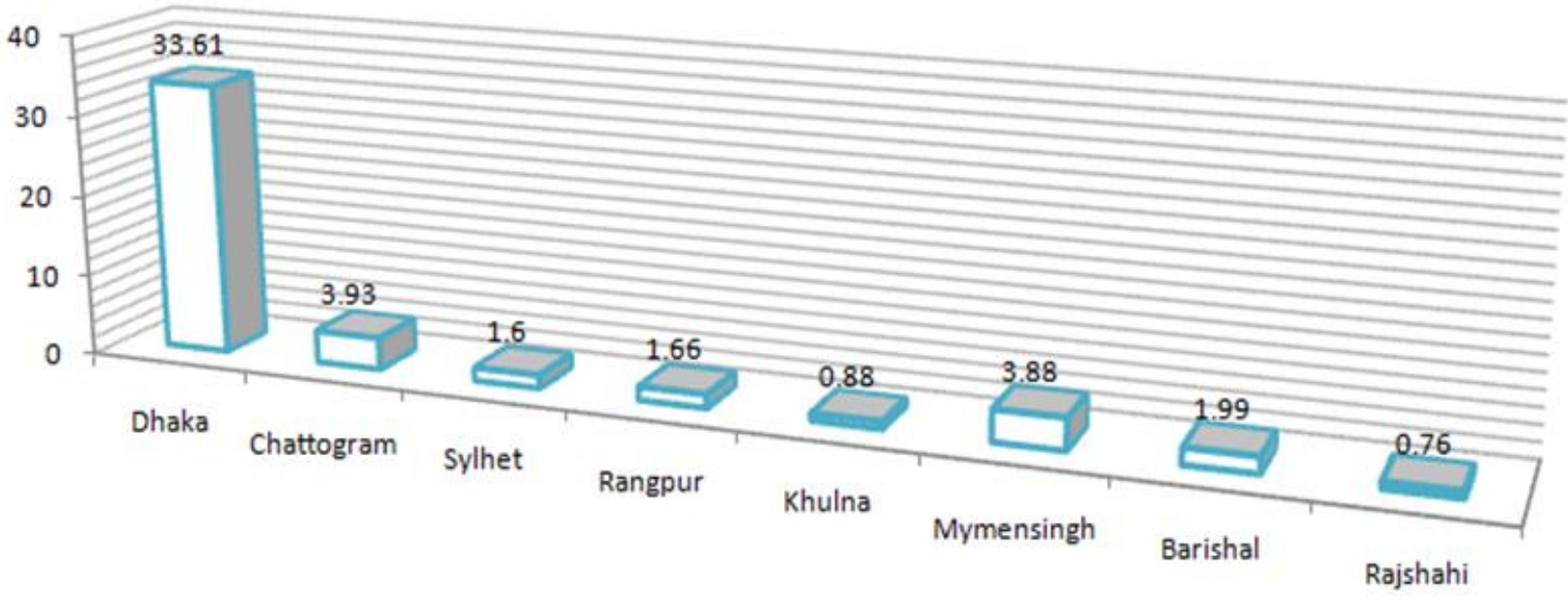

Figure-7. Comparison of daily confirmed cases according to Divisions (From 08 March, 2020 to 25 April, 2020). Source: IEDCR (April, 2020).

The Novel Coronavirus disease (COVID-19) pandemic was confirmed to have spread to Bangladesh on March 2020 for the first time. Bangladesh experienced first three confirmed cases on 8 March, 2020 reported by Institute of Epidemiology, Disease Control and Research (IEDCR, 2020). Infection was is infant stage till the end of the March but it steep rise in the first week of April month. But it is a matter of serious concern that, at the ending of the week at 11 April, new cases in Bangladesh increased by almost 1,155 percent. The numbers of confirmed cases are going upward day by day. Bangladesh experienced a highest level of confirmed cases still now on 24 April, 2020 which was 503 cases in a day. Still now the numbers of total tested cases are 42,813 among which number of total confirmed cases is 4,998. Among the total confirmed cases only 112 is recovered whereas 140 infected patients were dead till 25 April, 2020 (IEDCR, April 2020). Figure 3, 4, 5, 6 shows the number of total confirmed cases (in cumulative and day statistics) and number of total deaths (in cumulative and day statistics). Figure 7 shows the number of confirmed cases according to divisions of Bangladesh. As per the statistics on 25 April, 2020 the highest confirmed cases was identified in Dhaka division (almost 33.61 percent). The second affected division is Chattogram division with 3.93 percent and in third position there is Mymensingh division along with 3.88 percent. The lowest affected division is Rajshahi which holds 0.76 percent of total confirmed cases in Bangladesh according to the statistics made by Institute of Epidemiology, Disease Control and Research (IEDCR, April, 2020). Bangladesh faces significant challenges in fighting against COVID-19 pandemic as it is a densely populated country with largest population size and also houses a million stateless Rohingya refugees in sprawling refugee camps that are conducive to the spread of epidemics. It also has significant migrant populations living in Italy, a COVID-affected country. Bangladesh Government has taken several significant steps to reduce the severity of this pandemic.

\subsection{Consequences of Novel Coronavirus (COVID-19) on Mental Health}

Prior studies conducted by several researchers have found evidence that, there is detrimental impact of any pandemic on the mental health of general people living in that region.

At the time of the Ebola outbreaks ${ }^{1}$ in Sierra Leone in 2014 and in the Democratic Republic of the Congo in 2018, the country experiences a high level of anxiety among the medical staffs and there was an adverse impact of stigma among those people who were in direct touch with infected patients (Park et al., 2018). In another research study Lee et al. (2018) argued that, during the outbreak of SARS-CoV 2 in Taiwan in 2003, the staffs who were working in emergency department and psychiatric ward have shown more severe PTSD symptoms. So there was a

Ebola virus disease (EVD), formerly known as Ebola hemorrhagic fever, is a severe, often fatal illness affecting humans and other primates.

${ }^{2}$ Severe acute respiratory syndrome (SARS) is a viral respiratory illness caused by a coronavirus called SARS-associated coronavirus (SARS-CoV). 
crying need of the development of post-traumatic stress disorder (PTSD) ${ }^{3}$ during the outbreak. When the Korean MERS-CoV ${ }^{4}$ outbreak happened during the year 2015 it was observed that, the impacts of stigma and robustness had a significant negative impact on the mental health of health professionals working on public hospitals (Shigemura et al., 2020).

Panagioti, Yardley, Schlotz, and Michie (2020) conducted a research study in which they claimed that, there may have an injurious impact of pandemic and its related issues namely home quarantine, self isolation, social distancing, lockdown etc. on the psychological health of the people. A number of metal disorders like schizophrenia, metal stress, depression etc. may be caused by the aloneness and interrupting on social interactions during the time of pandemic. People experiences severe anxiety about their personal health, health of their beloved persons and also for their uncertain future which is another root cause for exacerbate fear, depression and various types of psychological problems.

Another researchers (Fiorillo \& Gorwood, 2020) disclosed that, social dishonor and discrimination towards the people who are infected by the COVID-19 pandemic and their family members is another considerable factors which is responsible for psychotically pressure or mental stress among the peoples who are not infected by the pandemic yet now. They are always tensed about their infection and loosing of social dignity and people's attitude towards them. So the researchers concluded their study by arguing that, fighting social stigma toward those treating and caring for people with COVID-19 should be another main concern for mental health professionals during the pandemic. In the urgent situation of COVID-19, the personnel who are working in health sectors had rendered their services in high risk of infection without adequate protection. They had to pay overwork, kept them isolated, maintained patients with negative emotions and had less opportunity to contract with their family all of which consequently leads to the severe stress and mental disorder among themselves (Kang et al., 2020). The research findings of Kang et al. (2020) supported by others researchers (Jones, Thompson, Schetter, \& Silver, 2017) fighting against any pandemic may create serious mental health problems likewise depressive symptoms, anxiety, stress, insomnia, denial, anger and fear. These mental disorders may also hinder the fighting of that particular pandemic.

When any community crisis emerged, people are interested to know event related information in order to stay informed about what is going on the surroundings. In this circumstances if information from official channel is inadequate or not properly conveyed to the people then they go for alternative option most preferably rely on social media for getting the necessary information. But all of the information transmitted in the social media may not be authentic which consequently may increase mental pressure among the people. A study conducted on a university lockdown in the United States after a shooter incident showed that, those subjects receiving conflicting information about the lockdown reported much higher levels of acute stress (Purgato et al., 2018). In this study the researchers emphasis on the significance of disclosing substantive official updates on a regular basis and monitoring the information provided in social media to prevent fake information to reduce mental stress and anxiety.

Fiorillo and Gorwood (2020) found in his research that, the psychosocial consequences of the COVID-19 pandemic may be particularly serious for those people who have been directly or indirectly in contact with the virus or those who are already vulnerable to biological or psychosocial stressors (including people affected by mental health problems) or those who are health professionals (because of higher level of exposure) or those people who are following the news through numerous media channels.

\footnotetext{
${ }^{s}$ Post-traumatic stress disorder (PTSD) is a disorder that develops in some people who have experienced a shocking, scary, or dangerous event. 'Middle East respiratory syndrome (MERS) is a viral respiratory disease caused by a novel coronavirus (Middle East respiratory syndrome coronavirus, or MERS-CoV) that was 


\section{METHODOLOGY OF THE STUDY}

The present study is quantitative in nature which was basically designed to explore the consequences of novel coronavirus (COVID-19) on mental health. The population of the study consists of general people living in Dhaka and Mymensingh city. The study considered convenient sampling method ${ }^{5}$ for choosing the sample size. From the total population 1000 respondents from Dhaka and Mymensingh districts were selected as targeted sample size. In order to assess mental health the study basically measure three variables namely depression, anxiety and stress among the residents of Dhaka and Mymensingh city. Depression Anxiety and Stress Scale (DASS- 21) was administered to reflect the mental health of the target respondents. DASS is a reliable tool to appraise the psychological distress in clinical and non-clinical population (Osman et al., 2012). The study was basically conducted on the basis of primary data. A self-administered structured questionnaire was served to the respondents through creating a Google form for the purpose of collecting necessary data. The questionnaire was sent to the target respondents through E-mail and social media especially face book. The questionnaire was structuring according to DASS-21 scale measurement. The collected data analyzed by using SPSS 23.0 and MS Excel 2007. Descriptive statistics used for defining the demographic characteristics of respondents. For checking the internal consistency and reliability of data Cronbach's Alpha test has done.

\section{DATA ANALYSIS AND FINDINGS}

\subsection{Demographic Analysis of the Respondents}

Table 1 shows that, $(n=1000,73.2 \%)$ of the respondents are male and rest of them $(n=1000,26.8 \%)$ are female. The study has collected data from different aged people to reflect the actual response and avid any biased response. The demographic characteristics regarding age of the respondents are as follows, less than 30 years are $(n=1000$, $30.1 \%)$, age ranged from 31-40 years are $(n=1000,27.9 \%)$, aged ranged from $41-50$ years are $(n=1000,321.7 \%)$ and above 50 years are $(\mathrm{n}=1000,20.3 \%)$. The table also shows the marital condition status of the target respondents in where single are $(n=1000,34.3 \%)$, married are $(n=1000,51.3 \%)$, divorce are $(n=1000,5.7 \%)$ and rest of the respondents are widow $(\mathrm{n}=1000,8.7 \%)$. The study collected data from 1000 respondents of which $101 \mathrm{are} \mathrm{PhD}$ completed $n=1000,10.1 \%), 609$ are masters completed $n=1000,60.9 \%), 103$ are honors completed $n=1000,10.3 \%$ ), 156 are HSC completed $n=1000,15.6 \%$ ), and rest of the 31 are SSC completed $n=1000,3.1 \%)$. The study also found from the total respondents 774 are employed $(n=1000,77.4 \%)$ and 226 are unemployed $(n=1000,22.6 \%)$. The study tried to collect data from different professionals from all sectors to get a biased free response and measure the perception of the respondents from different professions with different age, education level and cultures. The demographic features regarding profession of the respondents shows that, the study has collected data from 84 scientist or researchers $(n=1000,8.4 \%), 114$ doctors or medical staffs $(n=1000,11.4 \%), 103$ administrators $(n=1000$, 10.3\%), 67 defense person $(n=1000,6.7 \%), 131$ teachers $(n=1000,13.1 \%)$ from different universities and colleges, 98 corporate persons $(n=1000,9.8 \%), 81$ bankers $(n=1000,8.1 \%), 76$ engineers $(n=1000,7.6 \%), 20$ businessman $(n=1000,2.0 \%), 186$ students $(n=1000,18.6 \%)$ and 40 from others including housewives $(n=1000,4.0 \%)$.

\subsection{Reliability Test of Data}

A reliability test has been done to check the reliability and internal consistency of the collected data. Table 2 shows the result of reliability test which considers three variables namely depression, anxiety and stress of the target respondents. 
Table-1. Demographic Characteristics of respondents.

\begin{tabular}{|c|c|c|c|}
\hline Demographic Characteristics & Frequency & Percentage (\%) & Cumulative Percentage (\%) \\
\hline \multicolumn{4}{|l|}{ Gender $(n=1000)$} \\
\hline Male & 732 & 73.2 & 73.2 \\
\hline Female & 268 & 26.8 & 100.0 \\
\hline \multicolumn{4}{|l|}{ Age $(n=1000)$} \\
\hline Less than 30 Years & 301 & 30.1 & 30.1 \\
\hline $31-40$ Years & 279 & 27.9 & 58.0 \\
\hline 41-50 Years & 217 & 21.7 & 79.7 \\
\hline More than 50 Years & 203 & 20.3 & 100.0 \\
\hline \multicolumn{4}{|l|}{ Marital Status $(\mathrm{n}=1000)$} \\
\hline Single & 343 & 34.3 & 34.3 \\
\hline Married & 513 & 51.3 & 85.6 \\
\hline Divorce & 57 & 5.7 & 91.3 \\
\hline Widow & 87 & 8.7 & 100.0 \\
\hline \multicolumn{4}{|l|}{ Educational Qualification $(\mathrm{n}=1000)$} \\
\hline $\mathrm{SSC}$ & 31 & 3.1 & 3.1 \\
\hline $\mathrm{HSC}$ & 156 & 15.6 & 18.7 \\
\hline Honors/ Bachelors & 103 & 10.3 & 29.0 \\
\hline Master & 609 & 60.9 & 89.9 \\
\hline PhD/ Post Doc. & 101 & 10.1 & 100.0 \\
\hline \multicolumn{4}{|l|}{ Employment Status $(n=1000)$} \\
\hline Employed & 774 & 77.4 & 77.4 \\
\hline Unemployed & 226 & 22.6 & 100.0 \\
\hline \multicolumn{4}{|l|}{ Profession $(n=1000)$} \\
\hline Scientist/Researcher & 84 & 8.4 & 8.4 \\
\hline Doctor/ Health Staff & 114 & 11.4 & 19.8 \\
\hline Administrator & 103 & 10.3 & 30.1 \\
\hline Defense Person & 67 & 6.7 & 36.8 \\
\hline Teacher & 131 & 13.1 & 49.9 \\
\hline Corporate Person & 98 & 9.8 & 59.7 \\
\hline Banker & 81 & 8.1 & 67.8 \\
\hline Engineer & 76 & 7.6 & 75.4 \\
\hline Businessman & 20 & 2.0 & 77.4 \\
\hline Students & 186 & 18.6 & 96.0 \\
\hline Others & 40 & 4.0 & 100.0 \\
\hline
\end{tabular}

Table-2. Results of reliability analysis.

\begin{tabular}{c|c|c}
\hline Variables & No. of Items & Cronbach's Alpha $(\boldsymbol{\alpha})$ \\
\hline Depression & 7 & 0.842 \\
\hline Anxiety & 7 & 0.761 \\
\hline Stress & 7 & 0.713 \\
\hline
\end{tabular}

Table 2 explains the reliability test result. Cronbach's Reliability checking is very much necessary for checking the validity of data (Nunnally, 1978). In addition, the study estimates shows that a value range from 0.60 to 0.84 supports the minimum criteria of 0.60 for all Cronbachs' products (Hair, Ringle, \& Sarstedt, 1998). Table 2 shows the alpha value for all the variables are greater than standard value which means that, all the data collected under three variables are internally consistent.

\subsection{DAAS Measurement}

Table 3 shows the depression, anxiety and stress level of general people due to COVID-19 infections living in Dhaka and Mymensingh city according to their gender status. From the table the researchers found that, male respondents have moderate depression level (SV in between 14-20) whereas; female respondents have mild depression level (SV in between 10-13). The table also shows that, female respondents suffers from severe anxiety problem (SV in between 15-19) whereas, male respondents suffers from moderate anxiety level (SV in between 10- 
14). The study founds, the stress level among males are more severe ( $\mathrm{SV}$ in between 26-33) in comparison to females as their stress level is moderate (SV in between 19-25). The $\mathrm{P}$ value for all the variables are smaller than .005 which indicates that, there is a significant difference among gender in regard to depression, anxiety and stress level.

Table-3. Mental health of the respondents according to gender status.

\begin{tabular}{l|c|c|c}
\hline \multirow{2}{*}{ Gender Category } & \multicolumn{3}{|c}{ Scale Value (SV) } \\
\cline { 2 - 4 } & Depression & Anxiety & Stress \\
\hline Male & 15.00 & 10.00 & 28.25 \\
\hline Female & 13.00 & 16.25 & 24.75 \\
\hline P value & .000 & .000 & .001 \\
\hline & $(\mathrm{n}=1000)$ & & \\
\hline
\end{tabular}

Table-4. Mental health of the respondents according to age status.

\begin{tabular}{l|c|c|c}
\hline \multirow{2}{*}{ Age Category } & \multicolumn{3}{|c}{ Scale Value (SV) } \\
\cline { 2 - 4 } & Depression & Anxiety & Stress \\
\hline Less than 30 Years & 8.25 & 8.75 & 13.25 \\
\hline 31-40 Years & 15.00 & 14.25 & 21.75 \\
\hline $41-50$ Years & 14.75 & 13.00 & 20.25 \\
\hline More than 50 Years & 22.25 & 17.25 & 27.00 \\
\hline P value & .000 & .002 & .000 \\
\hline & $(\mathrm{n}=1000)$ & & \\
\hline
\end{tabular}

Table 4 shows the depression, anxiety and stress level of general people due to COVID-19 infections living in Dhaka and Mymensingh city according to their age status. The table depicts that, the people aged from more than 50 years are severely depressed (SV in between 21-27) due to COVID-19 pandemic in comparison to all other aged peoples whereas people aged from 31-50 years are moderately depressed (SV in between 10-13) and less than 30 years old people are suffering from normal depression level (SV in between 0-9). Similarly in case of anxiety level, people aged from more than 50 years suffers from severe anxiety (SV in between 15-19) and all other aged people except less than 30 years suffers from moderate anxiety level (SV in between 10-14). The study also found that, stress level is more severe among the people aged more than 50 years (SV in between 26-33) and for 31-50 years old people stress level is moderate (SV in between 19-25) whereas as people aged less than 30 years suffer from mild stress level (SV in between 15-18). The $\mathrm{P}$ value for all the variables are smaller than .005 which indicates that, there is a significant difference among age in regard to depression, anxiety and stress level.

Table-5. Mental health of the respondents according to marital status.

\begin{tabular}{l|c|c|c}
\hline \multirow{2}{*}{ Marital Status Category } & \multicolumn{3}{|c}{ Scale Value (SV) } \\
\cline { 2 - 4 } & Depression & Anxiety & Stress \\
\hline Single & 9.00 & 10.25 & 16.25 \\
\hline Married & 24.50 & 16.25 & 27.50 \\
\hline Divorce & 17.25 & 12.00 & 20.25 \\
\hline Widow & 19.25 & 17.50 & 26.00 \\
\hline P value & .000 & .000 & .002 \\
\hline & $(\mathrm{n}=1000)$ & & \\
\hline
\end{tabular}

Table 5 shows the depression, anxiety and stress level of the respondents on the basis of their marital status. The study found that, among the total respondents the respondents who are married are severely depressed than the others (SV in between 21-27). The level of depression among divorce and widow are moderate (SV in between 14-20) and in case of single man or women depression level is comparatively normal in relation to others (SV in between 0-9). The table also shows severe anxiety level among the married and widow peoples (SV in between 1519) whereas, moderate anxiety level for both single and divorce peoples (SV in between 10-14). The stress scale 
value shows 27.50 and 26.00 for married and widow respondents which depicts that, these two categories respondents are feeling stressed severely (SV in between 26-33). In another point the stress level for divorce and single respondents are in moderate (SV in between 19-25) and mild ( $\mathrm{SV}$ in between 15-18) respectively. The $\mathrm{P}$ value for all the variables are smaller than .005 which indicates that, there is a significant difference among marital status in regard to depression, anxiety and stress level.

Table-6. Mental health of the respondents according to educational qualification status.

\begin{tabular}{l|c|c|c}
\hline \multirow{2}{*}{ Educational Qualification Category } & \multicolumn{3}{|c}{ Scale Value (SV) } \\
\cline { 2 - 4 } & Depression & Anxiety & Stress \\
\hline SSC & 21.50 & 16.25 & 27.50 \\
\hline HSC & 15.25 & 11.75 & 18.25 \\
\hline Honors/ Bachelors & 17.75 & 12.75 & 16.50 \\
\hline Master & 14.25 & 10.25 & 20.25 \\
\hline PhD/ Post Doctorate & 18.25 & 13.75 & 21.50 \\
\hline P value & .000 & .001 & .007 \\
\hline
\end{tabular}

Table 6 shows the depression, anxiety and stress level of the respondents on the basis of their educational qualification. The research findings demonstrates that, the depression level is severe for less educated respondents passed SSC degree (SV in between 21-27) and moderate for rest of the respondents (SV in between 14-20). As like as depression, the anxiety level is also severe (SV in between 15-19) among SSC qualified respondents whereas rest of the respondents shows their anxiety level as moderate (SV in between 10-14). The research findings also shows that, stress among SSC qualified peoples are severe (SV in between 26-33) and for other comparatively less severe. The $\mathrm{P}$ value for all the variables except stress are smaller than .005 which indicates that, there is a significant difference among educational qualification status in regard to depression and anxiety level where as $\mathrm{P}$ value for stress is .007 which is greater than .005 indicates that, there is no significant difference among the educational qualification in regards to stress.

Table-7. Mental health of the respondents according to employment status.

\begin{tabular}{l|c|c|c}
\hline \multirow{2}{*}{ Employment Category } & \multicolumn{3}{|c}{ Scale Value (SV) } \\
\cline { 2 - 4 } & Depression & Anxiety & Stress \\
\hline Employed & 15.00 & 12.25 & 17.25 \\
\hline Unemployed & 16.25 & 13.00 & 20.50 \\
\hline P value & .005 & .008 & .012 \\
\hline & $(\mathrm{n}=1000)$ & & \\
\hline
\end{tabular}

Table-8. Mental health of the respondents according to professional status.

\begin{tabular}{|c|c|c|c|}
\hline \multirow[t]{2}{*}{ Professional Category } & \multicolumn{3}{|c|}{ Scale Value $(\mathrm{SV})$} \\
\hline & Depression & Anxiety & Stress \\
\hline Scientist/Researcher & 16.50 & 12.75 & 20.75 \\
\hline Doctor/ Health Staff & 16.75 & 18.25 & 30.50 \\
\hline Administrator & 19.75 & 14.25 & 20.25 \\
\hline Defense Person & 21.75 & 20.50 & 29.75 \\
\hline Teacher & 19.50 & 13.75 & 22.25 \\
\hline Corporate Person & 13.25 & 12.50 & 20.25 \\
\hline Banker & 21.75 & 19.75 & 27.50 \\
\hline Engineer & 13.75 & 13.25 & 20.25 \\
\hline Businessman & 28.50 & 21.75 & 32.75 \\
\hline Students & 12.25 & 8.50 & 14.25 \\
\hline Others & 12.75 & 8.00 & 13.25 \\
\hline \multirow[t]{2}{*}{$\mathrm{P}$ value } & .000 & .000 & .000 \\
\hline & $(\mathrm{n}=1000)$ & & \\
\hline
\end{tabular}


Table 7 shows the depression, anxiety and stress level of the respondents on the basis of their employment status. From the table it can be depicted that, for employed people depression level is moderate (SV in between 1420), anxiety level is moderate (SV in between 10-14) and stress level is mild (SV in between 15-18) whereas for unemployed people depression, anxiety and stress level is also moderate. The $\mathrm{P}$ value for all the variables are greater than .005 which indicates that, there is no significant difference among employment status in regard to depression, anxiety and stress level.

\subsection{Summary of Findings}

Table 8 shows the depression, anxiety and stress level of the respondents on the basis of their professional status. The research findings reveal that, depression level is extremely severe for businessman (SV is 28+), severe for defense persons and bankers (SV in between 21-27) whereas depression level is moderate for scientist/ researchers, doctors/health staffs, administrator, teacher and corporate persons (SV in between 14-20) and mild for engineer, students and others (SV in between 10-13). The table also shows that, defense persons and businessman suffer from extreme anxiety ( $\mathrm{SV}$ is $20+$ ), doctors/medical staffs and bankers suffer from severe anxiety (SV in between 15-19), scientist/ researchers, administrators, teachers, corporate persons, engineers suffer from moderate anxiety (SV in between 10-14) whereas, students and other suffer from mild level of anxiety (SV in between 8-9). The research findings get severe stress among doctors/health staffs, defense persons, bankers, businessman (SV in between 26-33) whereas moderate stress among scientists/researchers, administrators, teachers, corporate persons and engineers (SV in between 19-25). The stress level among students and other respondents are normal (SV in between $0-14$ ). The $\mathrm{P}$ value for all the variables are smaller than .005 which indicates that, there is a significant difference among professional status in regard to depression, anxiety and stress level.

\section{CONCLUSION}

The study disclosed that, novel coronavirus disease (COVID-19) pandemic has a significant influence on psychological health of the peoples living in studied area. As people are bound to stay at their home due to lockdown restrictions so they are going through a crisis situation and felling uncertainty about their career and professional life. The study found extremely severe anxiety and depression among the businessman because in this present situation they are not able to conduct their business which forces them to a great uncertainty and crisis. The study also pointed that, the anxiety level is higher in females whereas males are more depressed and stressed as compared to females which is supported by the findings of National Mental Health of India. From the Table 9 we can get a summary of the findings of the study. The people who are old aged generally more than 50 years are getting severe depressed, anxious and stressed in comparison to other aged peoples. Research arch findings also shows that, married people are more severely depressed, anxious and stressed than the others most probably for the concern of their bread and butter and supporting the family members. There is variation of depression, anxiety and stress level according to professions. The research findings reveal that, depression level is extremely severe for businessman and severe for defense persons and bankers whereas depression level is moderate for scientist/ researchers, doctors/health staffs, administrator, teacher and corporate persons.

\section{RECOMMENDATIONS}

One of the probable ways of reducing risk of mental health is to avoid the fake and unrealistic information sometimes conveyed by social media. So people can rely on a limited amount of official information sources that are reliable and authentic. The researchers also recommend breaking the isolation by increasing the communication with friends, family members, and loved ones, even if at a distance for ensuring sound mental health. Video-chat or group calls with family members may assist in reducing loneliness and shakiness. In this critical moment, people may keep a regular routine by emphasizing regular sleep-awake rhythms and diet patterns. They may make a 
regular routine for their worship and prayer to the Almighty for improving the situation. The study also recommends that, the people should focus on physical isolation or maintaining social distance by feeling that, this isolation is not only protecting their health rather than also for protecting others from the pandemic. If required, people may ask for psychiatric help or consultation.

Table-9. Summary of findings.

\begin{tabular}{|c|c|c|c|}
\hline Demographic Characteristics & Depression & Anxiety & Stress \\
\hline \multicolumn{4}{|l|}{ Gender Status } \\
\hline Male & Moderate & Moderate & Severe \\
\hline Female & Mild & Severe & Moderate \\
\hline \multicolumn{4}{|l|}{ Age Status } \\
\hline Less than 30 Years & Normal & Normal & Mild \\
\hline $31-40$ Years & Moderate & Moderate & Moderate \\
\hline $41-50$ Years & Moderate & Moderate & Moderate \\
\hline More than 50 Years & Severe & Severe & Severe \\
\hline \multicolumn{4}{|l|}{ Marital Status } \\
\hline Single & Normal & Moderate & Mild \\
\hline Married & Severe & Severe & Severe \\
\hline Divorce & Moderate & Moderate & Moderate \\
\hline Widow & Moderate & Severe & Severe \\
\hline \multicolumn{4}{|l|}{ Educational Qualification Status } \\
\hline $\mathrm{SSC}$ & Severe & Severe & Severe \\
\hline HSC & Moderate & Moderate & Mild \\
\hline Honors/ Bachelors & Moderate & Moderate & Mild \\
\hline Master & Moderate & Moderate & Moderate \\
\hline PhD/ Post Doc. & Moderate & Moderate & Moderate \\
\hline \multicolumn{4}{|l|}{ Employment Status } \\
\hline Employed & Moderate & Moderate & Mild \\
\hline Unemployed & Moderate & Moderate & Moderate \\
\hline \multicolumn{4}{|l|}{ Professional Status } \\
\hline Scientist/Researcher & Moderate & Moderate & Moderate \\
\hline Doctor/ Health Staff & Moderate & Severe & Severe \\
\hline Administrator & Moderate & Moderate & Moderate \\
\hline Defense Person & Severe & Extremely Severe & Severe \\
\hline Teacher & Moderate & Moderate & Moderate \\
\hline Corporate Person & Moderate & Moderate & Moderate \\
\hline Banker & Severe & Severe & Severe \\
\hline Engineer & Mild & Moderate & Moderate \\
\hline Businessman & Extremely Severe & Extremely Severe & Severe \\
\hline Students & Mild & Mild & Normal \\
\hline Others & Mild & Mild & Normal \\
\hline
\end{tabular}

\section{LIMITATIONS AND FUTURE SCOPE}

One of the limitations of the study is to use self-report tool (DASS-21) for estimating the mental health namely, depression, anxiety and stress which may not be as effective as being determined by trained mental health professionals. The study conducted on the basis of data collected from only two districts Dhaka and Mymensingh, adding the another limitation of the study. To overcome the limitations of the present study, future researches may be conducted by several researchers in more extensive approach. There is also scope for future researchers to conduct study by taking more sample size from different areas.

Funding: This study received no specific financial support.

Competing Interests: The authors declare that they have no competing interests.

Acknowledgement: Both authors contributed equally to the conception and design of the study. 


\section{REFERENCES}

Brooks, S. K., Webster, R. K., Smith, L. E., Woodland, L., Wessely, S., Greenberg, N., \& Rubin, G. J. (2020). The psychological impact of quarantine and how to reduce it: Rapid review of the evidence. The Lancet, 395(10227), 912-920.Available at: https://doi.org/10.1016/s0140-6736(20)30460-8.

Chen, Y., Liu, Q., \& Guo, D. (2020). Emerging coronaviruses: genome structure, replication, and pathogenesis. Journal of Medical Virology, 92(4), 418-423.Available at: https://doi.org/10.1002/jmv.25681.

Corman, V. M., Landt, O., Kaiser, M., Molenkamp, R., Meijer, A., Chu, D. K., Schmidt, M. L. (2020). Detection of 2019 novel coronavirus (2019-nCoV) by real-time RT-PCR. Eurosurveillance, 25(3), 2000045.

Cui, J., Li, F., \& Shi, Z.-L. (2019). Origin and evolution of pathogenic coronaviruses. Nature Reviews Microbiology, 17(3), 181192.Available at: https://doi.org/10.1038/s41579-018-0118-9.

Cullen, W., Gulati, G., \& Kelly, B. (2020). Mental health in the Covid-19 pandemic. QJM: An International Journal of Medicine, $113(5), 311-312$.

Fiorillo, A., \& Gorwood, P. (2020). The consequences of the COVID-19 pandemic on mental health and implications for clinical practice. European Psychiatry, 63(1), e32.Available at: https://doi.org/10.1192/j.eurpsy.2020.35.

Hair, J. F., Ringle, C. M., \& Sarstedt, M. (1998). Partial least squares structural equation modeling: Rigorous applications, better results and higher acceptance. Long Range Planning, 46(1-2), 1-12.

Jones, N. M., Thompson, R. R., Schetter, C. D., \& Silver, R. C. (2017). Distress and rumor exposure on social media during a campus lockdown. Proceedings of the National Academy of Sciences, 114(44), 11663-11668.Available at: https://doi.org/10.1073/pnas.1708518114.

Kang, L., Li, Y., Hu, S., Chen, M., Yang, C., Yang, B. X., . . Ma, X. (2020). The mental health of medical workers in Wuhan, China dealing with the 2019 novel coronavirus. The Lancet Psychiatry, 7(3), e14.Available at: https://doi.org/10.1016/s22 15-0366(20)30047-x.

Lee, N., Bushmaker, T., Morris, D. H., Holbrook, M. G., Gamble, A., Williamson, B. N., \& Lloyd-Smith, J. O. (2018). Aerosol and surface stability of SARS-CoV-2 as compared with SARS-CoV-1. New England Journal of Medicine, 382(16), 1564-1567.

Li, X., Song, Y., Wong, G., \& Cui, J. (2020). Bat origin of a new human coronavirus: There and back again. Science China Life Sciences, 63(3), 461-462.Available at: https://doi.org/10.1007/s11427-020-1645-7.

Lu, H., Stratton, C. W., \& Tang, Y.-W. (2020). Outbreak of pneumonia of unknown etiology in wuhan China: The mystery and the miracle. Journal of Medical Virology, 92(4), 401-402.Available at: https://doi.org/10.1002/jmv.25678.

Nunnally, J. C. (1978). Validity and reliability in social science research. Education Research and Perspectives, 38(1), 105.

Osman, A., Wong, J. L., Bagge, C. L., Freedenthal, S., Gutierrez, P. M., \& Lozano, G. (2012). The depression anxiety stress Scales-21 (DASS-21): Further examination of dimensions, scale reliability, and correlates. Journal of Clinical Psychology, 68(12), 1322-1338.Available at: https://doi.org/10.1002/jclp.21908.

Panagioti, E., Yardley, L., Schlotz, W., \& Michie, S. (2020). The importance of coping appraisal in behavioural responses to pandemic flu. British Journal of Health Psychology, 17(1), 44-59.

Park, J. H., Rivière, I., Gonen, M., Wang, X., Sénéchal, B., Curran, K. J., . . Mead, E. (2018). Long-term follow-up of CD 19 CAR therapy in acute lymphoblastic leukemia. New England Journal of Medicine, 378(5), 449-459.Available at: https://doi.org/10.1056/nejmoa1709919.

Purgato, M., Gastaldon, C., Papola, D., Van Ommeren, M., Barbui, C., \& Tol, W. A. (2018). Psychological therapies for the treatment of mental disorders in low-and middle-income countries affected by humanitarian crises. Cochrane Database of Systematic Reviews(7).

Ryu, S.-H., \& Chun, B.-C. (2020). An interim review of the epidemiological characteristics of 2019 novel coronavirus. Epidemiology and Health, 42(1), e2020006.Available at: https://doi.org/10.4178/epih.e2020006.

Shigemura, J., Ursano, R. J., Morganstein, J. C., Kurosawa, M., \& Benedek, D. M. (2020). Public responses to the novel 2019 coronavirus (2019-nCoV) in Japan: Mental health consequences and target populations. Psychiatry and Clinical Neurosciences, 74(4), 281-282.Available at: https://doi.org/10.1111/pcn.12988. 
Torales, J., O’Higgins, M., Castaldelli-Maia, J. M., \& Ventriglio, A. (2020). The outbreak of COVID-19 coronavirus and its impact on global mental health. International Journal of Social Psychiatry, 0020764020915212.Available at: https://doi.org/10.1177/0020764020915212.

Zhu, N., Zhang, D., Wang, W., Li, X., Yang, B., Song, J., Tan, W. (2020). A novel coronavirus from patients with pneumonia in China, 2019 New England Journal of Medicine, 382, 727-733. 